\title{
Chlorine: Is it really so bad and what are the alternatives?
}

\author{
SD Freese* and DJ Nozaic \\ Umgeni Water, PO Box 9, Pietermaritzburg 3200, South Africa
}

\begin{abstract}
Chlorine disinfection has been practised for over a century and has been credited with saving a significant number of lives worldwide on a daily basis, but it has received a great deal of negative publicity over the past few decades. The discovery in the 1970's that chlorination of water could result in the formation of potentially harmful trihalomethanes (THMs) caused concern amongst the water treatment fraternity and resulted in authorities reviewing chlorination practices in order to minimise THM formation and the United States Environmental Protection Agency (USEPA) setting maximum concentration limits for THMs in potable water. Many of the manufacturers and suppliers of water "purifiers" and alternative disinfectants exploit this information to their own advantage, misinforming the public regarding the dangers of chlorine, but even in the water treatment industry, chlorine is often misunderstood. Based on their experience in both water and wastewater disinfection and on the findings of a Water Research Commission (WRC) sponsored project into alternative disinfectants, the authors discuss the benefits and disadvantages of chlorine disinfection and compare this to the more promising alternative disinfectants. One of the main perceived advantages is the property of chlorine to maintain a residual and although THM formation can occur under these conditions, the compounds produced are perceptibly less toxic than those produced by some of the alternatives. A number of alternatives, including ozone, UV, peracetic acid, bromine and advanced oxidation are compared to chlorine in terms of their disinfectant abilities, residual effect, by-product formation, cost and ease of use.
\end{abstract}

\section{Introduction}

One of the first documented uses of chlorine was in 1850 by John Snow when he used it to disinfect a water supply in London after an outbreak of cholera (White, 1999). Some years later in the 1890s, hypochlorites were used in Europe as a provisional measure against typhoid epidemics (Baker, 1930) and in 1897 hypochlorite "bleach solution" was used by Sims Woodhead to treat potable water after an outbreak of typhoid in Kent, England (Leal, 1909). Continuous chlorination of potable water supplies began in the early years of the $20^{\text {th }}$ Century in Great Britain and resulted in a dramatic reduction in deaths due to typhoid and other water-borne diseases and shortly thereafter, in 1908, Jersey City, New Jersey began chlorinating potable water supplies. Since then, chlorine has become the most widely used disinfectant for water treatment worldwide, because of its potency, relative ease of use and cost effectiveness.

More recently, chlorine has received negative publicity, mainly due to the discovery in the 1970's that chlorination of water containing organic compounds could lead to the formation of trihalomethanes (THMs), which are suspected of having detrimental health effects (White, 1999). Manufacturers and suppliers of water filtration devices and alternative disinfectants have used this information to their advantage, sometimes even employing scaremongering techniques and generally misinforming the general public regarding chlorine disinfection. This paper discusses the benefits and disadvantages of chlorine disinfection, attempts to put the THM concerns into proper perspective and based on the findings of a WRC sponsored project which was recently conducted by the authors, describes various alternative options avail-

This paper was originally presented at the 2004 Water Institute of South Africa (WISA) Biennial Conference, Cape Town, South Africa, 2-6 May 2004.

* To whom all correspondence should be addressed.

酉+2733 3968033; fax:+2733 3968033; e-mail: sue.freese@umgeni.co.za able for disinfection and how they compare to chlorine in terms of disinfection efficiency and cost.

\section{The importance of disinfection}

The importance of disinfecting potable water cannot be underestimated. Life Magazine (Life Magazine, 1998) ranked water purification and disinfection $46^{\text {th }}$ in its list of top one hundred advances of the millennium. The true value of disinfection first became evident as early as 1893, when two public health researchers, Mills and Reincke, after studying a large number of communities, discovered that when a contaminated water supply was replaced with a purified water source, the general overall health of the community improved significantly, far beyond what would be expected by accounting for the reduced incidence of typhoid and other typical water-borne diseases. This discovery became known as the Mills-Reincke phenomenon (White, 1999). A few years later in 1903, a pioneer in the water works industry, Allen Hazen, found that when a community water supply of bad quality was replaced by an adequately treated one, for every life saved due to typhoid, three others were saved from death by other causes, many of which were not thought to have any connection with, or to be affected or influenced by, the quality of the public water supply. This change in the death rate once water is adequately treated is known as the Hazen theorem and proves that disinfection of public water supplies far exceeds the effect of controlling water borne diseases (White, 1999).

Numerous references can be found attesting to the significant beneficial effects of disinfection. Figures which put this effect into perspective come from the United States; in 1900 the death rate from typhoid was 36 per 100000 population, this dropped to 20 per 100000 in 1910, 3 per 100000 in 1935 and by 1960 only 20 people were recorded as having died from typhoid throughout the entire USA (Laubusch, 1964; Tiernan, 1948). Today, typhoid is virtually unknown in the USA and other developed countries. This dramatic reduction in the typhoid death rate can be attributed almost entirely 
to chlorination of potable water supplies. Similar figures exist for cholera, dysentery and other water-borne diseases and again, these are largely attributable to chlorination of potable water supplies. Unfortunately, untreated or inadequately treated potable water supplies are still the greatest threat to public health in developing countries, where it has been estimated that around half of the population do not have access to safe drinking water. Horrifying figures are stated for developing countries, such as 1990 figures for deaths in children under the age of five due to diarrhoeal diseases; a staggering three million (Christman, 2004). These figures can be largely ascribed to a lack of adequately disinfected water.

Prof. Thomas Packenham has stated that it has been conservatively estimated that in the region of 25000 lives are saved daily due to water chlorination already being practiced, but the figure may be as high as 70000 lives per day, so it is not surprising that many consider the production of adequately treated and disinfected water as one of the most effective public fund investments possible, providing excellent benefit to cost ratios.

\section{Chlorine disinfection}

White (1999) has stated that just as water is close to being a universal solvent, so chlorine is nearly a universal water treatment chemical. Chlorine is a very effective disinfectant, it is relatively easy to handle, the capital costs of chlorine installation are low, it is cost effective, simple to dose, measure and control and it has a relatively good residual effect. There are certainly other disinfectants that are equal to or even better than chlorine and the results of an investigation into these will be discussed later, but to date, no other disinfectant has been found which can compete with the overall versatility of chlorine.

Chlorine disinfection is generally carried out using one of three forms of chlorine or it can be generated on site. For small water treatment plants, calcium hypochlorite in the form of a dry powder or proprietary tablet-type dispenser can be used. This is more expensive than gaseous chlorine or hypochlorite solution, but can offer advantages in terms of convenience and low installation costs. On a cost per mass of active chlorine basis, chlorine in the form of a liquefied gas is the most cost effective option, but is better suited to larger, more sophisticated works. Using liquefied gas carries the risk of accidental leakage of the gas, which is why some plants opt for the more expensive sodium hypochlorite solution. On-site generation is well-suited to remote areas close to a cheap source of brine, although obviously an electrical supply is necessary (Water Quality and Treatment, 1990).

\section{Trihalomethanes}

In the 1970s it was discovered that chlorination of water containing organic compounds could result in the formation of THMs. The discovery arose out of a 1970 US Public Health Services (USPHS) survey into the levels of various organic compounds in potable water supplies. Widespread use of pesticides, herbicides and other petrochemicals had raised concerns regarding the effect of these organic chemicals on potable water supplies and the survey indicated that in many cases, these compounds exceeded the USPHS recommended limit for drinking water $(0.2 \mathrm{mg} / \ell$ in 1970$)$ (USPHS Report, 1970). As a result, the National Organics Reconnaissance Survey was undertaken and revealed that four THMs, chloroform, bromodichloromethane, dibromochloromethane and bromoform, occur fairly extensively in chlorinated waters in the USA (Symons et al., 1975). Researchers (Rook, 1974; Bellar et al., 1974) had already shown that the reaction of chlorine with some waters could lead to the formation of THMs.

\section{Health effects of trihalomethanes}

Chloroform, which is the most commonly formed THM during chlorination, is a known carcinogen (Pieterse, 1988) and can cause cancer if one is exposed to high concentrations of it over long periods of time. This obviously caused concern amongst the water treatment fraternity and resulted in water treatment authorities reviewing chlorination practices in order to minimise THM formation and in 1978 the USEPA set maximum concentration limits for chloroform in potable water at $0.10 \mathrm{mg} / \ell$.

However, chloroform is not considered an acute hazard to man at the low concentrations in which it is found in water (White, 1999). In addition, despite rigorous scientific research studies, no conclusive evidence has ever been found to prove that THMs, in the quantities in which they occur in drinking water, are harmful to humans. Over the past 25 years, numerous studies have been conducted into the potentially harmful health effects of THMs and particularly chloroform. For example, based on studies conducted on laboratory animals (mice, rats and rabbits) (Murray et al., 1979; Ruddick et al., 1983; Schwetz et al., 1974; Thompson et al., 1974), the margin of exposure for humans from the highest chloroform dose that produced no adverse effects, is estimated to be between 34500 and $43000 \mathrm{mg} / \mathrm{kg}$ per day. The margin of exposure is the difference in the concentration in tap water of the compound in question and the highest dose of this compound that produces no developmental toxicity (Tardiff et al., 1999). An average adult man, weighing between 70 and $90 \mathrm{~kg}$, would have to drink 8 glasses of water a day (around $1.5 \ell$ ) containing between 1500 and 2000 $\mathrm{mg} / \ell$ chloroform in order to ingest a dose the size of this margin of exposure. The fact that chloroform occurs in water in microgram quantities, many orders of magnitude lower than 1500 to 2000 $\mathrm{mg} / \ell$, clearly indicates the unlikely threat posed by this THM from potable water supplies.

Studies carried out into the toxicity of bromoform to rats (Ruddick et al., 1983; Gulati et al., 1989; Borzelleca and Carchman, 1982) found that doses as high as $100 \mathrm{mg} / \mathrm{kg}$-day caused no adverse developmental effects, with Gulati et al (1989) reporting no effects on fertility or reproduction at doses up to $200 \mathrm{mg} / \mathrm{kg}$-day. Similar figures are quoted for dibromochloromethane (Ruddick et al., 1983) and bromodichloromethane (Ruddick et al., 1983; Narotsky et al., 1992).

Tardiff et al. (1999) concluded that epidemiological studies concerning birth defects have to date produced conflicting and inconclusive evidence in showing a link to disinfection by-products (DBP) and that whenever a link has been found, there have always been confusing factors in the study that throw doubt on the reliability of the results. Two fairly recent studies (Bove et al., 1995; Klotz and Perch, 1998), which were both based on the same study population, could not reproduce each other's findings to produce statistically significant links with THMs and toxicity studies conducted on laboratory animals to investigate possible links between birth defects and various DBPs have not been successful in demonstrating any obvious association between them (Tardiff et al., 1999).

To further put the trihalomethane issue into perspective, consider the fact that a number of over-the-counter cough mixtures, available without prescription, contain chloroform in high concentrations. In order to ingest the same amount of chloroform as contained in a single dose (one or two teaspoons in most cases) of one of these cough mixtures, one would need to drink eight glasses 
of water per day for a year, assuming that the THM concentration of the water was at the maximum allowable limit of $100 \mu \mathrm{g} / \ell$.

Under the same conditions, one would need to consume eight glasses of water a day for 10 years to obtain the equivalent amount of chloroform in a bottle of cough mixture.

\section{Concerns over trihalomethanes}

It is incomprehensible that many people are so concerned about the health effects of THMs in their drinking water that they would consider not chlorinating their water, despite the fact that the many studies conducted to date have still failed to demonstrate any conclusive link between THMs in potable water and detrimental health effects, while overwhelming evidence exists to indicate the effectiveness of chlorine in destroying pathogenic organisms in water supplies. Still more surprising is that many of these people will happily smoke cigarettes at rates that numerous studies have clearly shown to drastically increase one's chances of contracting lung cancer.

Unfortunately the media hype around the THM issue has been of such proportions that it has on occasion resulted in the obvious benefits of disinfection being disregarded in favour of their perceived dangers. Perhaps the most disastrous example of this occurred in Peru in 1991. Based on epidemiological evidence suggesting a statistically weak link between the consumption of chlorinated drinking water and liver cancer (Murphy and Craun, 1990), Peruvian officials took the decision not to chlorinate much of their country's potable water supply. The ensuing cholera epidemic, which was a direct result of this decision, claimed some 4000 lives (Anderson, 1991).

Even in this country, scare-mongering tactics from the suppliers of alternative disinfectant options lead the Parliamentary Portfolio Committee on Water Affairs and Forestry to debate the need for chlorine disinfection. Various stakeholders in the water industry, including representatives from water authorities such as Rand Water, Umgeni Water, Sedibeng Water and City of Cape Town, as well as bodies such as the WRC, WISA and the Department of Water Affairs, attended a Portfolio Committee meeting where the issue of chlorine disinfection and the possible health effects of THMs were debated. It was only through a well-prepared rebuttal by the established water treatment industry that a potentially disastrous situation was avoided and the importance of continuing with chlorine disinfection was conveyed to the committee.

Other examples can be found where suppliers of alternative disinfectants have used the THM issue to persuade water treatment authorities to substitute chlorination with their own brand of disinfectant. Although there are certainly reputable companies offering well-proven disinfection alternatives, there have also been less principled dealers who have in some cases convinced relevant authorities to use products that are unsuitable, unproven, less cost effective and produce potentially worse DBPs or higher concentrations of DBPs than chlorine does. During the research project that the authors conducted into alternative disinfectants, they came into contact with a supplier of a "stabilised bromine solution", which was claimed to demonstrate a number of benefits over chlorine, including producing lower concentrations of THMs. Investigations conducted on the solution revealed that within a few days a significant proportion of the active bromine in the solution had in fact converted to bromates, compounds which have no disinfection ability and which have potentially worse health effects than THMs. If used for potable water disinfection it is obvious that the implications of using such a disinfectant could be disastrous. Furthermore, bromine is more reactive than chlorine in forming halogenated organics (White, 1999), so in certain waters can be expected to produce higher levels of THMs than chlorine. It needs to be pointed out though that successful bromination of wastewater is practised both locally and internationally, generally using a combination of ammonium bromide and chlorine.

Fortunately more rational judgements regarding the balance of benefits provided by chlorine disinfection are beginning to appear (White, 1999; MIT/Norwegian Chlorine Policy Study, 1993; Kleijn et al., 1997; Kirschner, 1994; Water Engineering and Management Report, 1995; Spotlight Report, 1999). Pieterse (1988), after a comprehensive review of the potential health risks of THMs, concluded that disinfection, even when weighed against the possible health effects of DBPs, still remains the most important consideration in ensuring the safety of potable water. This is borne out in practice as clearly demonstrated by the 1991 Peruvian tragedy mentioned above.

In a 1993 report to the USEPA, Dr. Robert Tardiff concluded that the risk of microbial disease from water is far greater than the risk posed by DBPs suspected of causing cancer in humans. There are significant differences: microbial diseases have a high incidence of occurrence, the period of time (latency) between exposure and illness is short and the chance that people will fall ill is much greater. In contrast, there is still no reliable evidence that DBPs do result in cancer in humans at the concentrations that they occur in drinking water and even if they do, the incidence is very low and the latency extended.

\section{The alternatives}

Based on the evidence presented above, it is obvious that disinfection of water is essential to the health and well-being of a society and it should also be apparent that chlorine is the disinfectant that has allowed water disinfection to be implemented on such a wide scale during the course of the last century. However, there are a number of other disinfectants that in some aspects are even better than chlorine. Umgeni Water in conjunction with the WRC recently completed a project in which various disinfectants were evaluated in terms of their suitability as a replacement for chlorine for wastewater disinfection. However, since the quality of the wastewater effluent was generally fairly good (see Table 1), matching that of many river and raw water sources, the results of this investigation could be expanded to include general water disinfection. Precise details of the experimental methodology are given in WRC Report No. 1030/1/03 (Freese et al., 2003).

A variety of disinfectants was investigated, including ozone, ultra violet irradiation (UV), peracetic acid, bromine, mixed oxidant generators, electrode systems and advanced oxidation in which ozone or UV irradiation were used in conjunction with other oxidants.

Based on the results of this investigation the following disinfectants were identified as showing potential:

- Ozone

- UV

- Peracetic acid

- Bromine

- Advanced oxidation

The electrode systems were claimed by the suppliers to use an applied electric field to generate free radicals, but much of the disinfecting effect appeared to be due to dissolution of their copper electrodes and the generation of chlorine from dissolved chlorides in the water, since tests using electrodes other than copper provided poor disinfection. The mixed oxidant generators were claimed to 


\begin{tabular}{|l|c|c|}
\hline \multicolumn{3}{|c|}{ TABLE 1 } \\
Typical water quality data for the wastewater \\
effluent used for disinfection tests \\
\hline Determinand & Units & Secondary \\
wastewater \\
effluent
\end{tabular}

produce oxidants and radicals other than hypochlorite, but no evidence of any "mixed oxidants" could be found. The units were found to be problematic to operate and appeared to be nothing more than electrolytic chlorinators. For these reasons, the electrode systems and mixed oxidant generators were not considered viable replacements for chlorine. In comparing the different disinfectants to chlorine, the "demand" dose is often used. This is the dose of a particular disinfectant that needs to be added in order to produce a measurable residual in the water.

\section{Ozone}

Ozone and chlorine were found to perform very similarly at their respective demand doses, giving 2 to 3 log reductions for most of the indicator organisms (coliforms, E. coli and total counts at $37^{\circ} \mathrm{C}$ and $22^{\circ} \mathrm{C}$ ), although chlorine was found to be more effective in removing faecal streptococci organisms and ozone was superior in the removal of coliphage organisms and parasitic cysts and oocysts. However, it needs to be stressed that the ozone demand dose was generally between 55 and $60 \%$ that of the chlorine dose in terms of mass per volume (i.e. as $\mathrm{O}_{3}$ or $\mathrm{Cl}_{2}$ ), indicating that ozone is a more effective disinfectant than chlorine, achieving better micro-organism removals at lower concentrations. The results of this investigation also indicated that the disinfection reactions are more rapid with ozone compared to chlorine, but do not always progress to completion as well, probably due to the short residual time of ozone.

Apart from the obvious benefit of being a more effective disinfectant than chlorine, ozone, being such a powerful oxidant, has additional advantages, being effective in reducing colours and odours, improving suspended solids removal, conditioning sludges and oxidising pesticides and herbicides (Masten and Davies, 1994). Ozone also has a number of disadvantages, perhaps the most important being the high capital cost of ozone, the fact that it must be generated on site (Masten and Davies, 1994; Isaac, 1996) and that it requires highly skilled staff in order to operate and maintain the ozone plant. Ozone also increases the biodegradability of water, which can result in regrowth problems in distribution systems, although this can be used to advantage in biological treatment together with granular activated carbon (Servais et al., 1994). Ozone does exert a disinfection residual, but this dissipates rapidly, so it is often necessary to use another disinfectant with a longer lasting residual to ensure no regrowth occurs in the distribution system. Furthermore, despite the fact that interest in ozone was generated due to concerns over THMs formed during chlorination, it has since been discovered that ozone also results in the formation of DBPs, especially non-halogenated DBPs such as aldehydes, ketones and carboxylic acids (Flessinger et al., 1980; Miltner et al., 1992; Krasner et al., 1993a; Meijers et al., 1993; Goel et al., 1995), many of which have been found to be mutagenic or carcinogenic (Andrews and Huck, 1994). Ozone also gives rise to the formation of bromates when bromide is present in the water (Miltner et al., 1992; Haag and Hoigne, 1983; von Gunten and Hoigne, 1992; Glaze et al., 1993; Krasner et al., 1993b; Kruithof et al., 1993; Siddiqui and Amy, 1993; von Gunten and Hoigne, 1994).

\section{UV}

Two types of UV systems are available commercially, low pressure and medium pressure mercury vapour lamps. Low pressure systems produce a narrow band of radiation at $253,7 \mathrm{~nm}$, which is close to the optimal wavelength for inactivation of micro-organisms, but these systems emit only around $40 \%$ of the power input. Medium pressure systems emit a much broader band of UV light, but at a much higher power output.

Tests were conducted on a variety of systems, including both low and medium pressure, but despite differences in lamp type and system design, the results obtained for all the systems tested were similar at similar UV doses. UV doses of between 40 and $70 \mathrm{~mJ} / \mathrm{cm}^{2}$ generally gave 2 to 3 log reductions in indicator organisms, which is as good as, if not slightly better than, that which could be achieved at chlorine doses of 1 to $2 \mathrm{mg} / \ell$ above the chlorine demand value, the dose range that would be typically used in water. An interesting finding of this investigation was that the coliphage organisms, which were used as indicators of viruses, proved to be very susceptible to UV, complete removal of these organisms being obtained at UV doses of $60 \mathrm{~mJ} / \mathrm{cm}^{2}$. Initial results indicated that UV is fairly effective against parasitic cysts and oocysts, but since these organisms occurred only infrequently during these tests, it was not possible to draw more definite conclusions.

It was clear from the results of these tests that it is the UV dose administered that is important, rather than the system used, but accurate measurement of the UV dose is essential. UV provides good disinfection provided that it is applied correctly and it can offer additional advantages in that many pathogenic organisms are more susceptible to UV than they are to chlorine (Sobsey, 1989; Kaur et al., 1994). The effectiveness of UV disinfection is however very dependent on the depth of the water being irradiated, the transmissivity and turbidity (Qualls et al., 1985) and the bacterial concentrations (Moreno et al., 1997), so large variations in the water quality, especially in turbidity, can be problematic when using UV disinfection. One of the disadvantages of UV is that although there is no technical limitation on the size of a UV plant, more units being added in for larger plants, the costs tend to become prohibitive at larger facilities because of the high operating costs (Rudd and Hopkinson, 1989). However, when using medium pressure units, far less lamps are required since the power output is much higher, so for larger plants, these units are recommended. 


\begin{tabular}{|l|l|l|l|c|}
\hline \multicolumn{5}{|c|}{ TABLE 2 } \\
\hline Disinfectant & Dose & Advantages & Disadvantages & Cost c/k \\
\hline Chlorine gas & $6 \mathrm{mg} / \ell$ & $\begin{array}{l}\text { Effective } \\
\text { Relatively easy to handle, } \\
\text { dose and measure } \\
\text { Cost effective } \\
\text { Provides good residual }\end{array}$ & THM formation & 3.87 \\
\hline Ozone & $2 \mathrm{mg} / \ell$ & $\begin{array}{l}\text { Effective } \\
\text { Strong oxidising agent }\end{array}$ & $\begin{array}{l}\text { High capital cost. DBPs } \\
\text { Increases biodegradability } \\
\text { Short-lived residual } \\
\text { Non-halogenated }\end{array}$ & 8.23 \\
\hline UV (medium) & $40 \mathrm{~mJ} / \mathrm{cm}^{2}$ & $\begin{array}{l}\text { Effective } \\
\text { Easy to handle } \\
\text { No chemical additives }\end{array}$ & $\begin{array}{l}\text { No residual } \\
\text { Dependent on WQ } \\
\text { High costs for large plants } \\
\text { Photoreactivation } \\
\text { Not easy to measure }\end{array}$ & 4.94 \\
\hline Peracetic acid & $6 \mathrm{mg} / \ell$ & $\begin{array}{l}\text { Effective } \\
\text { Provides a residual } \\
\text { Relatively easy to handle, } \\
\text { dose and measure } \\
\text { Relatively stable }\end{array}$ & $\begin{array}{l}\text { Not cost effective } \\
\text { (n) }\end{array}$ & 36 \\
\hline
\end{tabular}

The possibility of photoreactivation or regrowth of organisms exposed to sub-lethal doses of UV and the fact that UV provides no residual effect are further disadvantages of UV disinfection.

\section{Peracetic acid}

Peracetic acid was found to be an effective disinfectant, generally providing disinfection comparable to that obtained using chlorine at equivalent mass concentrations. This is in agreement with the findings of Veschetti and co-workers (1998), who found that peracetic acid and sodium hypochlorite have similar disinfection efficiencies against faecal and total coliforms, although they found peracetic acid to be less effective against faecal streptococci, while in this study peracetic acid was found to be at least as effective as chlorine in removing these organisms and in many cases slightly better. Peracetic acid was not found to be quite as effective as chlorine for inactivation of parasitic organisms.

Positive aspects of peracetic acid are that it is relatively stable if stored correctly and although there are risks associated with handling, it poses far less hazards than a disinfectant such as chlorine gas, In addition to this, peracetic acid provides a residual. Unfortunately, peracetic acid is not at present readily available in Southern Africa and so at this stage is not an economically feasible option, but one could expect prices to drop significantly if it should become more widely used.

\section{Bromine}

Bromine was found to have disinfection efficiency similar to that of chlorine when used on a mass equivalent basis, although initial indications are that bromine is not as effective as chlorine in removing faecal streptococci organisms. Tests to evaluate the effectiveness of bromine in removing parasitic cysts and oocysts were inconclusive due to the fact that these organisms were seldom present in the water during the period in which the tests were conducted. Bromine is usually applied by adding ammonium bromide together with chlorine, which oxidises the bromide to bromine. A "stabilised bromine" solution was also investigated, but despite the stabilisers that the manufacturer claimed to have added, this solution proved to be unstable, rapidly transforming to bromates and losing more than half its disinfection strength within two to three days of storage.

Despite the disinfection efficacy of bromine, its use for potable water is not generally recommended, although it has been used successfully for wastewater disinfection and in cooling towers. One of the few known cases in which bromine was used for potable water disinfection was at Irvington, California in 1938 (White, 1999). It was found to react so rapidly with the biofilms present on the pipe walls, that it was impossible to maintain a residual downstream of the application point. Furthermore, it imparted a strong, medicinal taste to the water and after a trial period, bromination was stopped (Riley and Skirrow, 1965). Another disadvantage of bromine is that a significant proportion of the bromine can be lost in side reactions with any organic matter present in the water, which can lead to DBP formation and, as was found in the case described above, it can cause unpleasant, medicinal tastes in the water.

\section{Advanced oxidation}

Advanced oxidation, using either ozone combinations or UV combinations were found to improve disinfection, although this was usually fairly small and could not justify the additional capital and running costs that would be incurred using two, instead of one disinfectant. No significant improvements in the inactivation of parasitic cysts or oocysts were noted when using combinations and 
in most cases increasing the ozone or UV dose could achieve the same disinfection as that achieved at lower doses using advanced oxidation. The additional benefits obtained using advanced oxidation would have to be carefully weighed up against the increased costs and based on the results of this study, were not considered practical.

\section{Cost comparison}

Based on the results of this study, ozone, UV and peracetic acid were selected as suitable options for potable water disinfection. In Table 2, these disinfectants are compared to chlorine in terms of performance and cost. The dosages are based on those found to provide adequate disinfection of the water used for this study, which had a high micro-organism load.

The costs for chlorine are based on the amortisation of an estimated capital cost of R400 000 for an $80 \mathrm{M} \ell / \mathrm{d}$ installation over 10 years at $12 \%$, which amounts to $0.23 \mathrm{c} / \mathrm{k} \ell$. This has been escalated by $15 \%$ to allow for maintenance, giving a cost of $0.27 \mathrm{c} /$ $\mathrm{k} \ell$. Added to this is the cost for $6 \mathrm{mg} / \ell$ chlorine at R6.00 per $\mathrm{kg}$, which amounts to $3.6 \mathrm{c} / \mathrm{k} \ell$, giving a total of $3.87 \mathrm{c} / \mathrm{k} \ell$.

The cost for ozone is based on the amortisation of an estimated capital cost of R5.75 million for a $10 \mathrm{~kg} / \mathrm{h}$ plant, which is calculated to be adequate for an $80 \mathrm{M \ell} / \mathrm{d}$ plant. Amortising over 10 years at $12 \%$ gives a cost of $3.36 \mathrm{c} / \mathrm{k} \ell$ and allowing $15 \%$ for maintenance increases this to $3.86 \mathrm{c} / \mathrm{k} \ell$. The cost of liquid oxygen at R2 500 per tonne with an ozone generation efficiency of $15 \%$, yields a cost of $3.33 \mathrm{c} / \mathrm{k} \ell$. The estimated electricity consumption at $30 \mathrm{c} / \mathrm{kWh}$ yields an electrical cost of $1.04 \mathrm{c} / \mathrm{k} \ell$, resulting in a total cost for ozonation of $8.23 \mathrm{c} / \mathrm{k} \ell$.

The cost for UV is based on a capital cost of R3 850000 for a 32 lamp $80 \mathrm{M \ell} / \mathrm{d}$ plant, amortised over 10 years at 12\%, which amounts to $2.25 \mathrm{c} / \mathrm{k} \ell$. Allowing for maintenance and lamp replacement at $35 \%$ of this, gives an estimated total of $3.04 \mathrm{c} / \mathrm{k} \ell$ and the estimated electricity consumption at $30 \mathrm{c} / \mathrm{kWh}$ adds $1.9 \mathrm{c} / \mathrm{k} \ell$ to this, giving a total of $4.94 \mathrm{c} / \mathrm{k} \ell$.

Capital costs for peracetic acid were considered negligible, since it could be added to the water using relatively simple and inexpensive dosing systems. At present peracetic acid could be purchased in solution form consisting of $15 \%$ peracetic acid and $23 \%$ hydrogen peroxide at a cost of around R12.00/kg, if purchased in bulk. However, at this price peracetic acid is not an economically viable option, being about $36 \mathrm{c} / \mathrm{k} \ell$, and despite the promising results obtained, the price would need to drop significantly before this could be considered for disinfection.

\section{Conclusions}

The conclusions drawn from the literature survey conducted on chlorine and chlorine DBPs and from the investigation conducted into alternative disinfectants are:

- There is still no conclusive evidence to indicate that THMs, at the levels at which they occur in potable water, pose any serious health threats.

- Chlorine disinfection has probably been the most successful mass medication ever administered and chlorination of water still provides obvious benefits to public health that greatly exceed the dangers posed by THMs.

- There are a number of alternative disinfectants available, many of which are superior to chlorine in some aspects.

- To date, there is still no disinfectant that offers as many advantages as chlorine in terms of convenience, reliability, ease of use and measurement, and cost effectiveness.

\section{References}

ANDERSON C (1991) Cholera Epidemic Traced to Risk Miscalculation. Nature 354, 255.

ANDREWS SA and HUCK PM (1994) Using fractionated natural organic matter to quantitate organic by-products of ozonation. Ozone Sci. \& Eng. 16 (1) 1-12.

BAKER MN (1930) The quest for pure water. J. AWWA.

BELLAR TA, LICHTENBERG JJ and KRONER RC (1974) The occurrence of organohalides in chlorinated drinking waters. J. AWWA 66703.

BORZELLECA JF and CARCHMAN RA (1982) Effects of Selected Organic Drinking Water Contaminants on Male Reproduction. Research Triangle Park, NC, USEPA, EPA 600/1-82-009, NTIS PB82-259847, Contract No. R804290.

BOVE FJ, FULCOMER MC, KLOTZ JB, ESMART J, DUFFICY EM and SAVRIN JE (1995) Public drinking water contamination and birth outcomes. Am. J. Epidemiol 141850.

CHRISTMAN K (2004) Report to the Chlorine Chemistry Council.

FLESSINGER F, RICHARD Y, MONTIEL A and MUSQUERE P (1980) Advantages and disadvantages of chemical oxidation and disinfection by ozone and chlorine dioxide. Proc. of the Int. Symp. on Water Supply and Health, Noordwijkerhout, Amsterdam, Aug. 28.

FREESE SD, BAILEY I and NOZAIC D (2003). The Evaluation of Alternative Disinfection Processes for the Removal of Protozoan Oocysts and Other Micro-organisms in the Treatment of Final Wastewater. Water Research Commission Report No. 1030/1/03.

GOEL S, HOZALSKI RM and BOUWER EJ (1995) Biodegradation of NOM: Effect of NOM source and ozone dose. J. AWWA 87 (1) 90-105.

GLAZE WH, WEINBERG HS and CAVANAGH JE (1993) Evaluating the formation of brominated DBPs during ozonation. J. AWWA 85 (1) 96-103.

GULATI DK, HOPE E, BARNES LH, RUSSEL S and POONASHA KB (1989) Bromoform reproductive and fertility assessment in Swiss CD-1 Mice when administered by Gavage. Research Triangle Park, NC, National Institute for Environmental Health Sciences, NTIS PB89-169254.

HAAG WR and HOIGNE J (1983) Ozonation of bromide-containing waters: Kinetics of formation of hypobromous acid and bromate. Environ. Sci. and Technol. 17 (5) 261-267.

ISAAC RA (1996) Disinfection dialogue: The evolving perception of need, benefits and detriments. Water Environ. and Technol. 8 (5) 67-72.

KAUR K, BOTT TR, HEATHCOTE R, KEAY G and LEADBEATER BSC (1994) Treatment of algal-laden water: Pilot plant experiences. J. Inst. Water and Environ. Mgmt. 8 (1) 22.

KIRSCHNER E (1994) Michigan panel rebuts chlorine ban proposal. C\&E News, 11 July 5.

KLEIJN R, TUKKER A and VAN DER VOET E (1997) Chlorine in the Netherlands: Part 1. An overview. J. Ind. Ecol. 195.

KLOTZ JB and PERCH LA (1998) Case-Control Study of Neural Tube Defects and Drinking Water Contaminants. New Jersey Dept. of Health and Senior Services, Trenton, NITS/PB98-111644.

KRASNER SW, SCLIMENTI MJ and COFFEY BM (1993a) Testing biologically active filters for removing aldehydes formed during ozonation. J. AWWA 85 (5) 62-71.

KRASNER SW, GLAZE WH, WEINBERG HS, DANIEL PA and NAJM IN (1993b) Formation and control of bromate during ozonation of waters containing bromide. J. AWWA 85 (1) 73-81.

KRUITHOF JC, MEIJERS RT and SCHIPPERS JC (1993) Formation, restriction of formation and removal of bromate. Water Supply $\mathbf{1 1}$ (3/4) 331-342.

LAUBUSCH EJ (1964) Chlorination and Other Disinfection Processes. Chlorine Institute, New York.

LEAL JL (1909) Sterilization plant of the Jersey City Water Supply. J. AWWA 100.

LIFE MAGAZINE (1998) The Life Millennium: The 100 Most Important Events and People of the Past 1000 Years. Friedman R (ed.) Time-Life Books, New York.

MASTEN SJ and DAVIES SHR (1994) The use of ozonation to degrade organic contaminants in wastewaters. Environ. Sci. Technol. 28 (4) 180A-185A. 
MEIJERS RT, VAN DER VEER AJ and KRUITHOF JC (1993) Degradation of pesticides by ozonation and advanced oxidation. Water Supply 11 (3-4) 309-320.

MILTNER J, SHUKAIRY HM and SUMMERS RS (1992) Disinfection by-product formation and control by ozonation and biotreatment. J. AWWA 84 (11) 53-62.

MIT/NORWEGIAN CHLORINE POLICY STUDY (1993) Dimension of Managing Chlorine in the Environment: Report of the MIT/Norwegian Chlorine Policy Study. MIT Centre for Technology, Policy and Industrial Development, Cambridge, MA 02139.

MORENO B, GONI F, FERNANDEZ O, MARTINEZ JA and ASTIGARRAGA M (1997) The disinfection of wastewater by ultraviolet light. Water Sci. Technol. 35 (11) 233-235.

MURPHY PA and CRAUN GF (1990) A review of recent epidemiological studies reporting associations between drinking water disinfection and cancer. Water Chlorination 6361.

MURRAY FJ, SCHWETZ BA, McBRIDE JF and STAPLES RE (1979) Toxicity of inhaled chloroform in pregnant mice and their offspring. Toxicol. Appl. Pharmacol 50515.

NAROTSKY MG, HAMBY BT, MITCHELL DS and KAVLOCK RJ (1992) Full-litter Resorptions Caused by Low-molecular wieght Halocarbons in F-344 Rats. The Teratology Society Thirty-Second Annual Meeting, June 27-July 2 and the Nuerobehavioural Teratology Society Sixteenth Annual Meeting, June 27-30, 1992.

PIETERSE MJ (1988) The potential health risk of trihalomethanes in drinking water: A perspective. S. Afr. J. Sci. 84 166-170.

QUALLS RG, OSSEFF SF, CHANG JCH, DORFMAN MH, DUMAIS DC and JOHNSON JD (1985) Factors controlling sensitivity in ultraviolet disinfection for secondary effluent. J. Water Poll. Cont. Fed. 57 1006-1011.

RILEY JP and SKIRROW G (1965) Chemical Oceanography 136 , Academic Press, New York.

ROOK JJ (1974) Formation of haloforms during chlorination of natural waters. Water Treatment and Examination 23 (2) 234.

RUDD T and HOPKINSON LM (1989) Comparison of disinfection techniques for sewage and sewage effluents. J. IWEM 3 612-618.

RUDDICK JA, VILLENEUVE DC, CHI I and VALLI VE (1983) A teratological assessment of four trihalomethanes in the rat. J. Environ. Sci. Health (Part B): Pesticides, food contaminants, and agricultural wastes, B18 333.

SCHWETZ BA, LEONG BKJ and GHERING PJ (1974) Embryo- and fetotoxicity of inhaled chloroform in rats. Toxicol. Appl. Pharmacol. 28442.
SERVAIS P, BILLEN P and BOUILLOT P (1994) Biological colonization of granular activated carbon filters in drinking water. J. Environ. Eng. 120 (4) 888-899.

SIDDIQUI MS and AMY GL (1993) Factors affecting DBP formation during ozone-bromide reactions. J. AWWA 85 (1) 63-72.

SOBSEY MD (1989) Inactivation of health-related microorganisms in water by disinfection processes. Water Sci. Technol. 21179.

SPOTLIGHT REPORT (1999) Dutch environmentalists agree to chlorine sustainability studies. Spotlight $\mathbf{5 6}$ CEFIC, Brussels, May, 1999.

SYMONS JM, BELLAR TA, CARSWELL JK, DEMARCO J, KROPP KL, ROBECK GG, SEEGER DR, SLOCUM CJ, SMITH BL and STEVENS AA (1975) National organics reconaissance survey for halogenated organics. J. AWWA 67 (11) 634-647.

TARDIFF RG, HUBNER RP, GALIK SA, McGORY N and LOWENSTEIN J (1999) Disinfection By-Products (DBP) and their Developmental Hazards and/or Risks to Human Health: Update Since Stage I DBP Negotiations Under the Safe Drinking Water Act. Prepared for The Chlorine Chemistry Council, Arlington, Va.

TIERNAN MF (1948) Controlling the Green Goddess. J. AWWA 401042.

THOMPSON DJ, WARNER SD and ROBINSON VB (1974) Teratology studies on orally administered chloroform in the rat and the rabbit. Toxicol. Appl. Pharmacol. 29348.

USPHS REPORT (1970) Community Water Suppy Study: Analysis of National Survey Finding. Bur. of Water Hygiene, Envir. Health Service USPHS, Dept. of HEW, Washington, DC.

VESCHETTIE, CUTILLID, BONADONNA L, LIBERA SD, OTTAVIANI M, MARTINI C, ALAIMO C, PIZZARI P and ANASTASI P (1998) Preliminary Results on the Possibility of Using Peracetic Acid as Disinfectant of Wastewater. AWT98-Advanced Wastewater Treatment, Recycling and Reuse, Milano, 14-16 September, 1998, 397-404.

VON GUNTEN U and HOIGNE J (1992) Factors Controlling the Formation of Bromate During Ozonation of Bromide-Containing Waters. $J$. Water SRT-Aqua 41 (5) 299-304.

VON GUNTEN U and HOIGNE J (1994) Bromate formation during ozonation of bromide-containing waters: Interaction of ozone and hydroxyl radical reactions. Environ. Sci. Technol. 28 1234-1242.

WATER ENGINEERING AND MANAGEMENT REPORT (1995) Total chlorine ban not supported by evidence. Water Eng. Manag. 14226.

WATER QUALITY AND TREATMENT: A HANDBOOK OF COMMUNITY WATER SUPPLIES (1990) $\left(4^{\text {th }}\right.$ edn.), AWWA, McGraw-Hill. WHITE GC (1999) Handbook of Chlorination and Alternative Disinfectants ( $4^{\text {th }}$ edn.) Wiley-Interscience, John Wiley and Sons Inc., NY. 